\title{
Identification and Treatment Optimization of Comorbid Depression in Rheumatoid Arthritis
}

\author{
Mellissa H. Withers • Louella T. Gonzalez • George A. Karpouzas
}

Received: May 8, 2017 / Published online: August 16, 2017

(C) The Author(s) 2017. This article is an open access publication

\begin{abstract}
Patients with rheumatoid arthritis (RA) suffer from high rates of depression but depression often remains undiagnosed and untreated among RA patients. Because of its high prevalence and its profound impact on functional disability and health-related quality of life, prompt recognition and management of comorbid depression is urgently needed in patients with RA. Rheumatologists face the challenge of addressing depression in their clinical interactions with patients. The purpose of this paper is to present the prevalence of comorbid depression in RA, to delineate the consequences of depression among RA patients, to discuss the barriers to the identification of depression among RA patients, and to outline a set of recommendations to identify and treat
\end{abstract}

CME article This article has associated CME accreditation, valid until August 2018. Please follow this link to access the activity: https://rheumatology. medicinematters.com/mmr1702/13447766.

Enhanced content To view enhanced content for this article go to http://www.medengine.com/Redeem/ 49F8F06034298630.

M. H. Withers $(\bowtie) \cdot$ L. T. Gonzalez

Keck School of Medicine, University of Southern

California, Los Angeles, CA, USA

e-mail: mwithers@usc.edu

G. A. Karpouzas

Harbor-UCLA Medical Center, Torrance, CA, USA comorbid depression that could be implemented within the rheumatology clinic setting. A comprehensive approach to the management of both physical and mental health needs of RA patients can aid in improving patient overall quality of life. New clinical protocols should be developed to include routine depression screening as part of the rheumatology visit. Patient education to address misconceptions, knowledge gaps, and destigmatize depression is also recommended. More counseling resources, including emotional support groups, are necessary to provide treatment for those suffering from depression. Such interventions could help mitigate disability, improve quality of life, patient function, and overall satisfaction.

Keywords: Depression; Mental health; Rheumatology

\section{INTRODUCTION}

Depression is a mood disorder that is characterized by sustained, long-term sadness, and a loss of interest in daily activities. Cognitive symptoms include loss of self-worth, hopelessness, while somatic symptoms can include fatigue, insomnia, and loss of appetite [1]. Not surprisingly, it is common for patients to experience depression upon diagnosis of a serious, lifelong chronic disease such as rheumatoid 
arthritis (RA). The prevalence of depression among RA patients ranges between $9.5 \%$ and $41.5 \%$ [2-11] depending on how it is defined and measured. Such rates may be much higher than in the general population; in the USA, $6.7 \%$ of adults reported experiencing depression in the past year [12].

Matcham et al. [9] found that depression affected between $14.8 \%$ and $38.8 \%$ of RA patients, depending upon the measurement tool. Depression was the most common comorbidity among RA patients in a study of 3920 patients in 17 countries by Dougados et al. [10]; $15 \%$ overall reported depression, but its prevalence varied widely among countries-from $2 \%$ in Morocco to 33\% in the USA [10]. Furthermore, studies from the USA have found higher rates of depression among RA patients who are racial/ethnic minorities and/or low-income, such as low-income Latino immigrants [13-22]. Other studies have reported that demographic characteristics that are significant predictors of depression among RA patients include female sex [23-25], younger age [6, 26-29], less education [6, 30, 31], and single marital status [32]. Onset of depression may be higher at the time of RA diagnosis [21, 33].

The purpose of this paper is to present the prevalence of comorbid depression in RA, to delineate the consequences of depression among RA patients, to discuss the barriers to the identification of depression among RA patients, and to outline a set of recommendations to identify and treat comorbid depression that could be implemented within the rheumatology clinic setting. This article is based on previously conducted studies and does not involve any new studies of human or animal subjects performed by any of the authors.

\section{Consequences of Comorbid Depression in RA}

Depression can have far-reaching negative implications for patient health and daily functioning in RA patients. Depressed RA patients report reduced pain thresholds and more severe pain and disability $[6,17,21,34-48]$. They further exhibit higher rates of medical services utilization and increased healthcare costs compared to non-depressed RA subjects [31, 32, 49]. RA patients with depression are also less likely to be adherent to medications [50-52], and more likely to have ineffective pain management [53]. Moreover, depression has also been associated with increased fatigue and sleep problems [53-55], myocardial infarction [56], higher risk of suicide $[57,58]$, and even death $[7,46,55,57,59]$ in patients with RA.

Depression has been shown to be a robust, potentially reversible, determinant of functional disability over time; indeed, clinically meaningful improvement in depression independently predicted equally relevant improvement in disability [60]. Increased disability or the loss of function, particularly in valued life activities such as work, social interactions, and family relationships, can translate to diminished overall quality of life for RA patients $[6,31,42,61-63]$. The literature demonstrates a clear pattern of association between levels of social restriction, depression, and RA [6, 28, 48, 64, 65]. Michaud and Wolfe [66] found that patients with both RA and depression are more likely to become work-disabled than patients with RA alone; in fact, depression was the most important comorbid condition affecting work-disability in patients with RA. Neugebauer et al. [67] found that low satisfaction with abilities (as a result of RA) was the most important predictor of depressive symptoms.

\section{Synergistic Relationship Between RA and Depression}

The relationship between depression and RA is bidirectional and synergistic; the impact of RA on patients' pain and overall functioning can contribute to depression, while chronic depression can also be exacerbated by RA $[68,69]$. Depression may lead to increased production of pro-inflammatory cytokines, contributing to an inter-relationship between depression and higher disease activity [57]. In a review of 31 studies comprising 16,922 patients with a chronic disease, including diabetes, coronary artery disease, congestive heart failure, asthma, 
COPD, osteoarthritis, and RA, Katon et al. [33] showed that when depression or anxiety overlapped with the chronic disease, patients reported a significantly higher number of medical symptoms compared to those with the chronic condition alone, even after controlling for severity of disease. Furthermore, the six studies reviewed relating specifically to RA showed that severe pain was significantly correlated with depression and anxiety even after controlling for inflammatory markers and demographics [33]. Wolfe and Michaud [7] found that a combined measurement of fatigue and widespread pain was the most important predictor of depression among RA patients.

\section{Coping with RA and Depression}

Depression and its associated impairments can contribute to feelings of helplessness, pessimistic outlook, or perceived lack of control over pain or RA [3]. For example, studies have demonstrated an association between depression and disease acceptance and/or perception of the severity of the disease among patients with RA. Pinto-Gouveia et al. [70] found that subjects who had better disease acceptance reported less pain, fewer physical limitations, and lower overall depression levels. Importantly, they noted that those with higher levels of acceptance had lower rates of development of depression. Rezai et al. [47] found in their study among $100 \mathrm{RA}$ patients in Iran that higher depression symptoms were associated with increased perceived pain, more negative illness perceptions, greater functional impairment, graver perceived consequences, and less control over the disease. The results suggested that the relationship between depression symptoms and pain was partially mediated by illness perception. The term "catastrophizing" is defined by a specific set of cognitive and emotional responses to pain, such as the degree to which a patient feels helpless when in pain, the tendency to ruminate about pain, and the propensity to magnify the threat value of pain [71-74]. In their review of 10 published articles relating to pain catastrophizing and depression among patients with chronic conditions,
Edwards et al. [74] found that in patients with RA, catastrophizing and depression were linked to increased pain, higher reported physical self-limitation, reduced likelihood of returning to work, less exercise, fewer health-promoting behaviors, lower thresholds and tolerance to pain, and more difficulties suppressing thoughts of pain.

\section{Diagnosing Depression in the Rheumatology Clinic}

The challenge of identification and management of depression within the rheumatology clinic is not insignificant. The recognition of depression among RA patients may be hampered by both systems-level and patient-level barriers alike [68, 75]. Depressive symptoms may appear clinically very similar to symptoms of RA, and when depression is not identified or treated, patients may misattribute the source of their symptoms to RA [68, 76]. At a patient-level, the range and continuum of depressive symptoms may be underappreciated [21]; even when RA patients recognize the symptoms of depression, they may be reluctant to broach the topic with the rheumatologist because of time constraints, lack of provider continuity in an academic training center, or because they feel that mental health concerns are best discussed with other providers [21]. Ethnic or underserved populations in particular may encounter additional barriers, including language, or the lack of psychotherapy services available in the public clinic setting [19-22]. A perhaps unique challenge that these patients face is disclosure of depression due to stigma associated with admission of a mental illness. In addition, most rheumatologists do not routinely screen their RA patients for depression because of time constraints, inadequate referral services, lack of training and confidence in dealing with mental health issues, or the belief that other healthcare professionals will handle mental health concerns of their patients $[68,75,76]$. Sleath et al. [75] reported that less than one in five severely depressed patients (PHQ-9 $>15$ ) had the opportunity to discuss their depression during RA clinic visits. Even when depression was 
addressed, the discussion was initiated by the patient and was fairly limited; not once during the 200 observed office visits did a rheumatologist bring up the topic of depression with the patient [75].

\section{Treatment of Depression Among RA patients}

Depression is a treatable disorder and the efficacy of pharmacological, psychological, and behavioral treatments for depression are well documented [6, 12, 68, 75-77]. However, more research is needed to determine which interventions may be most effective among patients with RA, as previous studies have had mixed results. Fiest et al. [78] examined eight controlled trials conducted in persons with RA and depression or anxiety; they concluded that the level of evidence was low to moderate as a result of risk of bias and small numbers. Among six pharmacological interventions for depression, the three with active comparators did improve depressive symptoms. The singular psychological trial did not improve depressive symptoms. In other studies, behavioral interventions have shown some promise in helping RA patients to cope with their disease-related impairments and negative emotional states that may interfere with quality of life [68]. A variety of behavioral interventions have been shown to improve disease management and daily functioning among depressed RA patients, including in-person education and counseling sessions, peer and emotional support groups, and Internet-based, self-help programs [6, 79]. Garfenski et al. [79] reported on an Internet-based cognitive behavioral self-help intervention on depression, anxiety, and coping self-efficacy in people with RA and found that, after only a 2-month follow-up period, the intervention significantly improved depression and anxiety and strengthened coping self-efficacy in RA patients. Emotional and peer support can also have a significant positive impact on depression, [21, 40]. Another approach receiving increasing attention is mindfulness meditation, which has been proven effective in several studies to help RA patients manage or overcome depression [6, 80, 81]. Zautra et al. [81] found that both cognitive behavioral therapy and affective interventions (such as mindfulness meditation and emotional regulation therapy) reduced depression among RA patients. Pradhan et al. [80] also found mindfulness meditation to be effective in alleviating psychological distress in RA patients.

Several studies have found that physical activity and exercise also hold promise in reducing depression among RA patients [82-85]. Neuberger et al. [84] found that exercise had a positive influence on depression in a randomized trial of 220 RA patients. Patients were randomized to class exercises, home exercises using videotapes, and the control group. After 12 weeks of exercise, the class exercise group had a statistically significant difference in overall symptoms (including depression) as compared to the control group. Herring et al. [85] conducted a systematic review of 90 randomized controlled studies evaluating the impact of exercise on participants with chronic diseases. The results demonstrated that physical exercise was related to a significant reduction in depressive symptoms among patients with chronic disease. The researchers also found that the largest reduction of depressive symptoms came from patients with moderately elevated depressive symptoms at baseline. Kelley and Kelley's [82] review of 29 published studies that included 2449 participants (1470 exercise and 979 control) with RA and other rheumatic diseases found that $51.7 \%$ of the studies evaluating the effects of exercise on depressive symptoms had results that were statistically significant $(p<0.05)$.

Considering the rapidly evolving ethnic landscape in the USA, cultural sensitivity and adaptation would be key elements for acceptance, adherence, and ultimately success of any depression intervention. This would require incorporation of culturally relevant references, assessment and tailoring of depression education on a patient level, exploration and understanding of cultural and personal beliefs around potential reasons for depression incidence and intensity, and ultimately fostering and building on attitudes of self-resilience and self-reliance [21]. 


\section{RECOMMENDATIONS}

Depression negatively impacts the health and well-being of RA patients. Therefore, new protocols for the identification and treatment of depression within the RA clinic setting could help advance management of RA, as well as improve patients' overall quality of life. We have several recommendations on how to improve identification and management of depression within the RA clinic setting.

First, early diagnosis and treatment of depression could help to promote optimal health and resilience. Patients may be at highest risk of depression at the time of RA diagnosis $[21,33,86]$. Rheumatologists and healthcare providers working with RA patients should be cognizant of this high-risk time period so that they can be alert for depressive symptoms among newly diagnosed RA patients. Furthermore, studies demonstrate that females, younger patients, and those from racial/ethnic minority groups may be at highest risk of developing RA; such groups may require increased monitoring by clinicians for depressive symptoms.

Second, it is critical to provide patients and their families with education about depression and how to identify the symptoms as early as possible after diagnosis in order to improve the likelihood of self-identification of depression among patients and families. Increased awareness can help prepare patients and their families for the possibility of depression and how to recognize it. This may also help address misconceptions and knowledge gaps, as well as reduce stigma associated with depression. Patients should be made aware of the association between RA and depression, and that many of the symptoms of depression may mimic RA. It is also important that they understand the range of potential symptoms, and the varying degrees of severity that patients who are depressed may experience. Patients should also be encouraged to discuss mental health issues with their rheumatologist. Raising public awareness about the increased risk of depression among patients suffering from RA and other chronic conditions could also help promote more help-seeking behaviors among patients, as well as potentially reduce community-level stigma associated with mental health issues.

Third, routine screening for depression should be implemented in rheumatology clinics. Empirically validated diagnostic procedures exist for identifying and managing depression. Such tools can be self-administered by patients within a relatively short timeframe. For example, brief instruments such as the Patient Health Questionnaire (PHQ9) [87] provide cutoff scores that have high specificity and sensitivity for detecting depressive disorder. Yet, such procedures are not routinely implemented in rheumatology practice, highlighting an important service delivery gap in clinical care $[68,74,75]$. Screening mechanisms should be implemented beginning at the time of RA diagnosis and screening should continue on a regular basis to assess depression over the course of a patient's care, even after the symptoms of RA are under control. Roubille et al. [69] reported the recommendations of the Canadian Dermatology-Rheumatology Comorbidity Initiative which examined comorbidities like depression among RA patients. Their main recommendations included more awareness of among healthcare providers with regard to the heightened risk of depression among RA patients, as well as the implementation of screening They also advised that providers should be aware of the synergistic relationship between RA and depression, specifically that symptoms of depression may affect disease activity measures and that disease symptoms may also affect depression scores [69].

Rheumatologists should incorporate depression identification and management plan into patient care plans. For example, if the patient's screening scores suggest mild depression, psychological intervention may not be necessary. The rheumatologist should follow-up with the patient during the next visit to determine if the depression has worsened. However, if the scores demonstrate that the patient is likely experiencing a more serious depressive disorder, consultation with a mental health professional is necessary. Behavioral medicine specialists, such as clinical psychologists or psychiatrists who 
have training in understanding the relationship between psychological factors and chronic disease, are the most qualified to serve RA patients with depression and to coordinate their care plans with rheumatologists [76]. A timely referral system should be established for patients who need to consult with a mental health professional who could give a definitive diagnosis and establish a management approach. Regular communication between the rheumatologist and mental health professional is required in order to effectively manage both issues.

Fourth, it is important for rheumatologists to consider a holistic approach to patient well-being and functioning. A thorough evaluation of patient's overall functioning necessitates examining more than just the management of pain; for patients, the perception of disability may involve much more than simply the absence of pain $[19,76]$. While disease control may reduce symptoms of depression among RA patients [69], clinicians should be aware that patients' own perceptions of RA, such as their level of impairment and the impact it has on daily functioning, are critical in terms of both their physical and mental health outcomes. More research is needed on the lived experiences of the patient and the personal meaning of their disease. For example, regardless of actual disease activity, studies have shown that patients who perceive lower levels of control over their conditions may feel more helplessness, which can contribute to higher rates of depression [47]. Providing opportunities for patients to develop coping strategies could help mitigate the impact of depression. Interventions should aim to develop these skills soon after diagnosis of RA, even before patients become depressed, so that the potential impact is lessened if patients experience depressive symptoms. Resilience and mastery over illness have been found to be critical in terms of helping RA patients overcome depression [48]. Highlighting the role that changes in functional status have in predicting the long-term psychological well-being of individuals with chronic illnesses such as RA, Neugebauer et al. [67] reported that the maintenance of valued activities is a critical factor in the psychological adjustment of RA patients.
Physical activity and social participation are also essential to patients' mental health and can improve depressive symptoms. Patients should be encouraged to participate in as many daily activities as possible. Studies have also highlighted the association and synergies between depression and the impact of RA in terms of impairment and daily functioning and have found that less restrictions and higher maintenance of social participation can help reduce depression among RA patients $[47,69]$. Support groups run by peers or health professionals may have utility in helping patients cope with RA and/or depression [21]. Interventions that incorporate exercise or physical activity for RA patients are also recommended, as these can be effective in improving depression [82-85].

More research is needed on intervention approaches specifically for RA patients that are realistic given the constraints within the healthcare setting and the patients' own unique challenges. While some recent clinical trials have tested behavioral intervention approaches for depression among this group, they have had mixed results. Clearly this is an area that needs more attention.

\section{CONCLUSIONS}

Depression often remains undiagnosed and untreated among RA patients. Rheumatologists face a major challenge of addressing depression in their clinical interactions with patients. As a result of the high prevalence, the wide range of negative consequences, cyclical nature, and the documented synergistic relationship between RA and depression, evaluating and addressing comorbidities of depression and RA is an essential part of RA care. A comprehensive approach to the management of both physical and mental health needs of RA patients is likely to yield the best health outcomes. Clinical protocols should include routine depression screening as part of the rheumatology visit. Further patient information and education to address misconceptions and knowledge gaps, as well as reduce stigma associated with depression, is also recommended. More counseling resources are also needed to provide 
treatment for those suffering from depression, which could help mitigate disability, improve quality of life, patient function, and overall satisfaction.

\section{ACKNOWLEDGEMENTS}

No funding or sponsorship was received for this study or the publication of this article. All named authors meet the International Committee of Medical Journal Editors (ICMJE) criteria for authorship for this manuscript, take responsibility for the integrity of the work as a whole, and have given final approval for the version to be published.

Disclosures. Dr Withers has no relevant financial relationships to disclose. Dr Gonzalez has no relevant financial relationships to disclose. Dr Karpouzas has no relevant financial relationships to disclose.

Compliance with Ethics Guidelines. This article is based on previously conducted studies and does not involve any new studies of human or animal subjects performed by any of the authors.

Open Access. This article is distributed under the terms of the Creative Commons Attribution-NonCommercial 4.0 International License (http://creativecommons.org/licenses/ by-nc/4.0/), which permits any noncommercial use, distribution, and reproduction in any medium, provided you give appropriate credit to the original author(s) and the source, provide a link to the Creative Commons license, and indicate if changes were made.

\section{REFERENCES}

1. American Psychiatric Association (APA). Diagnostic and statistical manual of mental disorders, 5 th edn. 2013. http://dsm.psychiatryonline.org/doi/book/ 10.1176/appi.books.9780890425596. Accessed 19 April 2017.
2. Dickens CA, McGowan L, Clark-Carter D, et al. Depression in rheumatoid arthritis: a systematic review of the literature with meta-analysis. Psychosom Med. 2002;64:52-60.

3. Covic T, Tyson G, Spencer D, Howe G. Depression in rheumatoid arthritis patients: demographic, clinical, and psychological predictors. J Psychosom Res. 2006;60:469-76.

4. Nicassio PM. Understanding the role and significance of gender differences in pain and depression in Chinese elders with osteoarthritis. Pain. 2007;130:6-7.

5. Isik A, Koca SS, Ozturk A, Mermi O. Anxiety and depression in patients with rheumatoid arthritis. Clin Rheumatol. 2007;26:872-8.

6. Clarke DM, Currie KC. Depression, anxiety, and their relationship with chronic diseases: a review of the epidemiology, risk, and treatment evidence. Med J Aust. 2009;191:S54-60.

7. Wolfe K, Michaud K. Predicting depression in rheumatoid arthritis: the signal importance of pain extent and fatigue, and comorbidity. Arthritis Rheum. 2009;61:667-73.

8. Lok EYC, Mok CC, Cheng CW, Cheung EFC. Prevalence and determinants of psychiatric disorders in patients with rheumatoid arthritis. Psychosomatics. 2010;51:338-338.e8.

9. Matcham F, Rayner L, Steer S, Hotopf M. The prevalence of depression in rheumatoid arthritis: a systematic review and meta-analysis. Rheumatology. 2013;52:2136-48.

10. Dougados M, Perrodeau E, Fayet F, et al. Impact of a nurse led program of patient self-assessment of disease activity on the management of rheumatoid arthritis: results of a prospective, multicentre, randomized, control trial (COMEDRA). Ann Rheum Dis. $2013 ; 72: 150$.

11. Eusden J, Matcham F, Hotopf M, et al. The relationship between mental health, disease severity, and genetic disorders in early rheumatoid arthritis. Psychosom Med. 2017. http://insights.ovid.com/ crossref?an=00006842-900000000-98839. Accessed 29 April 2017.

12. US National Institute of Mental Health. National Survey on Drug Use and Health (NSDUH). 2015. https://www.nimh.nih.gov/health/topics/ depression/index.shtml. Accessed 25 May 2017.

13. Escalante A, Rincon I, Mulrow CD. Symptoms of depression and psychological distress among Hispanics with rheumatoid arthritis. Arthritis Care Res. 2000;13:156-67. 
14. Del Rincon I, Battafarano DF, Arroyo RA, Murphy FT, Fischbach M, Escalante A. Ethnic variation in the clinical manifestations of rheumatoid arthritis: role of HLA-DRB1 alleles. Arthritis Rheum. 2003;49:200-8.

15. Bruce B, Fries JF, Murtagh KN. Health status disparities in ethnic minority patients with rheumatoid arthritis: a cross-sectional study. J Rheumatol. 2007;34:1475-9.

16. Yazici $Y$, Kautiainen $H$, Sokka T. Differences in clinical status measures in different ethnic/racial groups with early rheumatoid arthritis: implications for interpretation of clinical trial data. J Rheumatol. 2007;34:311-5.

17. Margaretten M, Yelin E, Imboden J, et al. Predictors of depression in a multiethnic cohort of patients with rheumatoid arthritis. Arthritis Rheumatol. 2009;61:1586-91.

18. Margaretten M, Barton J, Julian L, et al. Socioeconomic determinants of disability and depression in patients with rheumatoid arthritis. Arthritis Care Res. 2011;63:24-246.

19. Karpouzas GA, Dolatabadi S, Moran R, Li N, Nicassio M, Wiseman MH. Correlates and predictors of disability in vulnerable US Hispanics with rheumatoid arthritis. Arthritis Care Res (Hoboken). 2012;64:1274-81.

20. McBurney CA, Vina ER. Racial and ethnic disparities in rheumatoid arthritis. Curr Rheumatol Rep. 2012;14:463-71.

21. Withers M, Moran R, Nicassio P, Weisman M, Karpouzas G. Perspectives of vulnerable Hispanics with rheumatoid arthritis on depression: awareness, barriers to disclosure, and treatment options. Arthritis Care Res. 2015;67:484-92.

22. Katz PP, Barton J, Trupin L, et al. Poverty, depression, or Lost in translation? Ethnic and language variation in patient-reported outcomes in rheumatoid arthritis. Arthritis Care Res (Hoboken). 2016;68(5):621-8.

23. Dowdy SW, Dwyer KA, Smith CA, Wallston KA. Gender and psychological well-being of persons with rheumatoid arthritis. Arthritis Care Res. 1996;9:449-56.

24. Theis KA, Hootman JM, Helmick GG, et al. State-specific prevalence of arthritis-attributable work limitation-United States, 2003 (reprinted from MMWR, vol 56, pg 1045-1049, 2007). JAMA. 2007;298:2255-6.

25. Jacob L, Rockel T, Kostev K. Depression risk in patients with rheumatoid arthritis in the United Kingdom. 2017. http://www.medengine.com/
Redeem/C3F7F0602F129F4E. Accessed 29 April 2007.

26. Wright SJ, Barnard MU, Olson NY, Austin JS, Lindsley CB. Communication issues of young adults with arthritis. Arthritis Rheum. 1998;41:S250.

27. Packham JC, Hall MA, Pimm TJ. Long-term follow-up of 246 adults with juvenile idiopathic arthritis: predictive factors for mood and pain. Rheumatology. 2002;41:1444-9.

28. Plach SK, Napholz L, Kelber ST. Social, health, and age differences associated with depressive disorders in women with rheumatoid arthritis. Int J Aging Human Dev. 2005;61:179-94.

29. Patten SB, Williams JV, Lavorato DH, et al. Patterns of association of chronic medical conditions and major depression. Epidemiol Psychiatr Sci. 2016;27:1-9.

30. Evers AWM, Kraaimaat FW, Geenen R, Jacobs JWG, Bijlsma JWJ. Long-term predictors of anxiety and depressed mood in early rheumatoid arthritis: a 3 and 5 year follow up. J Rheumatol. 2002;29:2327-36.

31. Li X, Gignac MAM, Anis AH. The indirect costs of arthritis resulting from unemployment, reduced performance, and occupational changes while at work. Med Care. 2006;44:304-10.

32. Katz PP, Yelin EH. Prevalence and correlates of depressive symptoms among persons with rheumatoid arthritis. J Rheumatol. 1993;20:790-6.

33. Katon W, Lin E, Kroenkem K. The association of depression and anxiety with medical symptom burden in patients with chronic medical illness. Gen Hosp Psychiatry. 2007;29:147-55.

34. Katz PP, Yelin EH. The development of depressive symptoms among women with rheumatoid arthritis. The role of function. Arthritis Rheum. 1995;38:49-56.

35. Wolfe F. A reappraisal of HAQ disability in rheumatoid arthritis. Arthritis Rheum. 2000;43:2751-61.

36. Katz PP, Yelin EH. Activity loss and the onset of depressive symptoms: do some activities matter more than others? Arthritis Rheum. 2001;44:1194-202.

37. El-Miedany YM, El Rasheed AH. Is anxiety a more common disorder than depression in rheumatoid arthritis? Joint Bone Spine. 2002;69:300-6.

38. Cadena J, Vinaccia S, Perez A, Rico MI, Hinojosa R. The impact of disease activity on the quality of life, mental health status, and family dysfunction among Colombian patients with rheumatoid arthritis. J Clin Rheumatol. 2003;9:142-50. 
39. Covic T, Adamson B, Spencer D, Howe G. A biopsychosocial model of pain and depression in rheumatoid arthritis: a 12-month longitudinal study. Rheumatology. 2003;42:1287-94.

40. Neugebauer A, Katz PP. Impact of social support on valued activity disability and depressive symptoms in patients with rheumatoid arthritis. Arthritis Rheum. 2004;51:586-92.

41. Nakajima A, Kamitsuji S, Saito A, et al. Disability and patient's appraisal of general health contribute to depressed mood in rheumatoid arthritis in a large clinical study in Japan. Mod Rheumtaol. 2006;16:151-7.

42. Katz P, Morris A. Time use patterns among women with rheumatoid arthritis: association with functional limitations and psychology status. Rheumatology. 2007;46:490-5.

43. Smith BW, Zautra AJ. The effects of anxiety and depression on weekly pain in women with arthritis. Pain. 2008;138:354-61.

44. Atal SA, Ceceli E, Okumu M, et al. The evaluation of pain in patients with rheumatoid arthritis. Pain Pract. 2009;9:31.

45. Van't Land H, Verdurmen J, Ten Have M, et al. The association between arthritis and psychiatric disorders; results from a longitudinal population-based study. J Psychosom Res. 2010;68:187-93.

46. Morris A, Yelin EH, Panopalis P, et al. Long-term patterns of depression and associations with health and function in a panel study of rheumatoid arthritis. J Health Psychol. 2011;16:667-77.

47. Rezai F, Doost HTN, Molavi H, Abedi MR, Karimifar M. Depression and pain in patients with rheumatoid arthritis: mediating role of illness perception. Egypt Rheumatol. 2014;36:57-64.

48. Benka J, Nagyova I, Rosenberger J, et al. Social participation in early and established rheumatoid arthritis patients. Disabil Rehabil. 2016;38:1172-9.

49. Joyce AT, Smith P, Khandker R, Melin JM, Singh A. Hidden cost of rheumatoid arthritis (RA): estimating cost of comorbid cardiovascular disease and depression among patients with RA. J Rheumatol. 2009;36:743-52.

50. DiMatteo MR, Lepper HS, Croghan TW. Depression is a risk factor for noncompliance with medical treatment: meta-analysis of the effects of anxiety and depression on patient adherence. Arch Intern Med. 2000;160:2101-7.

51. McNamara D, Stebbings S, Highton J. Severe osteoarthritis is associated with similar fatigue and greater pain scores than rheumatoid arthritis, at comparable levels of disability. Rheumatology. 2007;46:160.

52. Julian LJ, Yelin E, Yazdany J, et al. Depression, medication adherence, and service utilization in systemic lupus erythematosus. Arthritis Rheum. 2009;61:240-6.

53. Nicassio PM, Ormseth SR, Kay M, et al. The contribution of pain and depression to self-reported sleep disturbance in patients with rheumatoid arthritis. Pain. 2012;153:107-12.

54. Katz P. Causes and consequences of fatigue in rheumatoid arthritis. Curr Opin Rheumatol. 2017;29:269-76.

55. Pincus T. Is mortality increased in patients with rheumatoid arthritis? J Musculoskelet Med. $1988 ; 5: 27-46$.

56. Scherrer JF, Virgo KS, Zeringue A, et al. Depression increases risk of incident myocardial infarction among veterans administration patients with rheumatoid arthritis. Gen Hosp Psych. 2009;31:353-9.

57. Fuller-Thomson E, Shaked Y. Factors associated with depression and suicidal ideation among individuals with arthritis or rheumatism: findings from a representative community survey. Arthritis Rheum. 2009;61:944-50.

58. Treharne GJ, Lyons AC, Kitas GD. Suicidal ideation in patients with rheumatoid arthritis: research may help identify patients at high risk. BMJ. 2000;321:1290.

59. Ang DC, Choi H, Kroenke K, Wolfe F. Comorbid depression is an independent risk factor for mortality in patients with rheumatoid arthritis. J Rheumatol. 2005;32:1013-9.

60. Karpouzas GA, Draper T, Moran R, et al. Trends in functional disability and determinants of clinically meaningful change over time in hispanic patients with rheumatoid arthritis in the US. Arthritis Care Res (Hoboken). 2017;69(2):294-8.

61. Bazzichi L, Maser J, Piccinni A, et al. Quality of life in rheumatoid arthritis: impact of disability and lifetime depressive spectrum symptomatology. Clin Exp Rheumatol. 2005;23:783-8.

62. Piccini A, Maser JD, Bazzichi L, et al. Clinical significance of lifetime mood and panic-agoraphobic spectrum symptoms on quality of life of patients with rheumatoid arthritis. Compr Psychiatry. 2006;47:201-8.

63. Ormseth SR, Draper TL, Irwin MR, et al. A multidimensional model of disability and role 
functioning in rheumatoid arthritis. Arthritis Care Res. 2015;67(12):1686-92.

64. Doeglas DM, Suurmeijer TPBM, van den Heuvel WJA, et al. Functional ability, social support, and depression in rheumatoid arthritis. Qual Life Res. 2004;13:1053-65.

65. Katz PP, Neugebauer A. Does satisfaction with abilities mediate the relationship between the impact of rheumatoid arthritis on valued activities and depressive symptoms? Arthritis Rheum. 2001;45:263-9.

66. Michaud K, Wolfe F. Comorbidities in rheumatoid arthritis. Best Pract Res Clin Rheumatol. 2007;21:885-906.

67. Neugebauer A, Katz PP, Pasch LA. Effect of valued activity disability, social comparisons, and satisfaction with ability on depressive symptoms in rheumatoid arthritis. Health Psychol. 2003;22(3):253-62.

68. Nicassio PM. The problem of detecting and managing depression in the rheumatology clinic. Arthritis Care Res. 2008;59:155-8.

69. Roubille C, Richer V, Starnino T, et al. Evidence-based recommendations for the management of comorbidities in rheumatoid arthritis, psoriasis, and psoriatic arthritis: expert opinion of the Canadian Dermatology-Rheumatology Comorbidity Initiative. J Rheumatol. 2015;42:1767-80.

70. Pinto-Gouveia J, Costa J, Maroco J. The first 2-years of rheumatoid arthritis: the influence of acceptance on pain, physical limitation and depression. J Health Psychol. 2013;20:102-12.

71. Linton SJ, Nicholas MK, MacDonald S, et al. The role of depression and catastrophizing in musculoskeletal pain. Eur J Pain. 2011;15(4):416-22.

72. Edwards RR, Bingham CO, Bathon J, Haythornthwaite JA. Catastrophizing and pain in arthritis, fibromyalgia, and other rheumatic diseases. Arthritis Rheum. 2006;55:325-32.

73. Evers AW, Verhoeven EW, van Middendorp H, et al. Does Stress affect the joints? Daily stressors, stress vulnerability, immune and HPA axis activity, and short-term disease and symptoms fluctuation in rheumatoid arthritis. Ann Rheum Dis. 2014;73:1683-8.

74. Edwards RR, Cahalan C, Mensing G, Smith M, Haythornthwaite JA. Pain, catastrophizing, and depression in rheumatic diseases. Nat Rev Rheumatol. 2011;7:216-24.
75. Sleath B, Chewning B, de Vellis BM, et al. Communication about depression during rheumatoid arthritis patient visits. Arthritis Rheum. 2008;15:186-91.

76. Nicassio PM, Irani M. Depression in rheumatoid arthritis. Rheumatologist. 2012. http://www.therheumatologist.org/article/depression-in-rheumatoid -arthritis/4/. Accessed 29 April 2017.

77. Cuijpers P, Andersson G, Donker T, et al. Psychological treatment of depression: results of a series of meta-analyses. Nord J Psychiatry. 2011;65:354-64.

78. Fiest KM, Hitchon CA, Bernstein CN, et al. Defining the burden and managing the effects of psychiatric comorbidity in chronic immunoinflammatory disease. Systematic review and meta-analysis of interventions for depression and anxiety in persons with rheumatoid arthritis. J Clin Rheumatol. 2017. doi:10.1097/RHU.0000000000000489.

79. Garfenski N, Kraaij V, Benoist M, Bout Z, Karels E, Smit A. Effect of a cognitive behavioral self-help intervention on depression, anxiety, and coping self-efficacy in people with rheumatic disease. Arthritis Care Res. 2013;65:1077-84.

80. Pradhan E, Baumgarten $M$, Langenberg $P$, et al. Effect of mindfulness-based stress reduction in rheumatoid arthritis patients. Arthritis Rheum. 2007;57:1134-42.

81. Zautra AJ, Davis MC, Reich JW, et al. Comparison of cognitive behavioral and mindfulness meditation interventions on adaptation to rheumatoid arthritis for patients with and without history of recurrent depression. J Consult Clin Psychol. 2008;76:408-21.

82. Kelley GA, Kelley KS. Exercise reduces depressive symptoms in adults with arthritis: evidential value. Med Sci Sports Exerc. 2016;48(5 Suppl 1):607.

83. Kelley GA, Kelley KS, Hootman JM. Effects of exercise on depression in adults with arthritis: a systematic review with meta-analysis of randomized controlled trials. Arthritis Res Therapy. 2015;17(1):21.

84. Neuberger GB, Aaronson LS, Gajewski B, et al. Predictors of exercise and effects of exercise on symptoms, function, aerobic fitness, and disease outcomes of rheumatoid arthritis. Arthritis Rheum. 2007;57(6):943-52.

85. Herring MP, Puetz TW, O'connor PJ, Dishman RK. Effects of exercise training on depressive symptoms among patients with a chronic illness: a systematic review and meta-analysis of randomized controlled trials. Arch Int Med. 2012;172:101-11. 
86. Maiden NL, Hurst NP, Lochhead A, Carson AJ, Sharpe M. Quantifying the burden of emotional ill-health amongst patients referred to a specialist rheumatology service. Rheumatology. 2003;42:750-7.
87. Kroenke K, Spitzer RL. The PHQ-9: a new depression and diagnostic severity measure. Psychiatr Ann. 2002;32(9):509-15. 